\title{
VARIA
}

\section{EL PEREGRINO DE LA VIDA HUMANA DEL BOSCO}

Dino Buzzati, y Cinotti, en su libro La obra pictórica completa del Bosco, publicada en 1968, resumen lo que todos los autores han aportado a propósito de la interpretación del "caminante» de la tapas del tríptico del Carro de Heno, como el vagabundo que sin preocuparse de su propia alma recorre los caminos de la tierra acosado por malvados y pecadores (Fig. 1). Solamente se apartan de esta crítica, Pigler que relaciona la figura con los «hijos de Saturno" -tesis inaceptada por la mayoría de los autores-y Brand Philip que la cree "figura demoníaca" 1.

La interpretación del protagonista y de la escena en general de las tapas del tríptico, como el "caminar de la humanidad", la pone en conexión con lo que se desarrolla en el interior de él, es decir con lo transitorio y caduco de la vida representado por el «heno" como símbolo y resumen de los placeres de la vida. Únicamente César Pemán piensa que no debe leerse la figura del «caminante" antes del tríptico abierto, sino después de cerrado, cuando ya ha recorrido el camino que «desde las delicias del Paraíso terrenal, a través del pecado original y de la serie de pecados implicados en la fábula moral del Carro de Heno, termina en los tormentos infernales» ${ }^{2}$ (Fig. 3).

Los críticos en general se esfuerzan en buscar una fuente literaria que respalde el tema del "caminante», inclinándose, muy preferentemente, por el Salmo 24,4 «Sean cubiertos de confusión todos aquellos que vana e injustamente obran la iniquidad. Muéstrame, oh Señor, tus caminos y enséñame tus senderos».

Recogen también algunos autores unos versos de la Bescheidenheit de Freidank que dicen "No sé bien quien soy, ni a donde debo ir», cuando se refieren al tema del Hijo Pródigo de Rotterdam. Bango y Marias, sin embargo, piensan, creo que con razón, que el tema del Salmo 13, 14, se ajusta más a la escena: «Dijo en su corazón el insensato: No hay Dios. Todos obran torpe-

1 D. Buzzati y M. Cinotti, La obra pictórica completa del Bosco. Barcelona. Madrid, 1968. Aunque recoge la bibliografía importante, se ha consultado y comprobado directamente la siguiente: J. Grauls, "Het Hooiwagen in de Beeldende Kunsten de Monogramist FB FHB en zijn verwanten FHB» (Gentsche Bijdragen... 1938, p. 141); D. Roggen, «J. Bosch: Literatuur en Folklore" (Gentsche Bijdragen..., 1939-40, p. 107); K. Seligman, "The Peddler» (Gazette des Beaux Arts, 1953, II, p. 97): L. Brand Philip, "The Peddler by Hieronimus Bosch. A Study in detection" (Nederlands Kunsthistorich Jaahrbock, 1958, p. 1); Bax, «Bezwaren tegen L. Brand Philips, interpretatis van Jeroen Bosch'Marskramer Goochelaar, Keisnijder en voorground van Hoowagen paneel» (Nederlands Kunsthistorich Jaahrboek, 1962, p. 1); C. Pemán, «Sobre la interpretación del Viandante del reverso del Carro de Heno de El Boscon (Archivo Español de Arte, 1961, p. 125; Ch. Tolnay, Hieronymus Bosch, London, 1966; J. K. Steppe, Hieronymus Bosch Exhibition Catalogue, S'Hertogenbosch, 1967, pp. 5-41; E. Calas, "Jheronimus Bosch and the parable of the two brothers» (Coloquio, 1978, p. 24).

${ }^{2}$ Loc. cit., nota 1. 


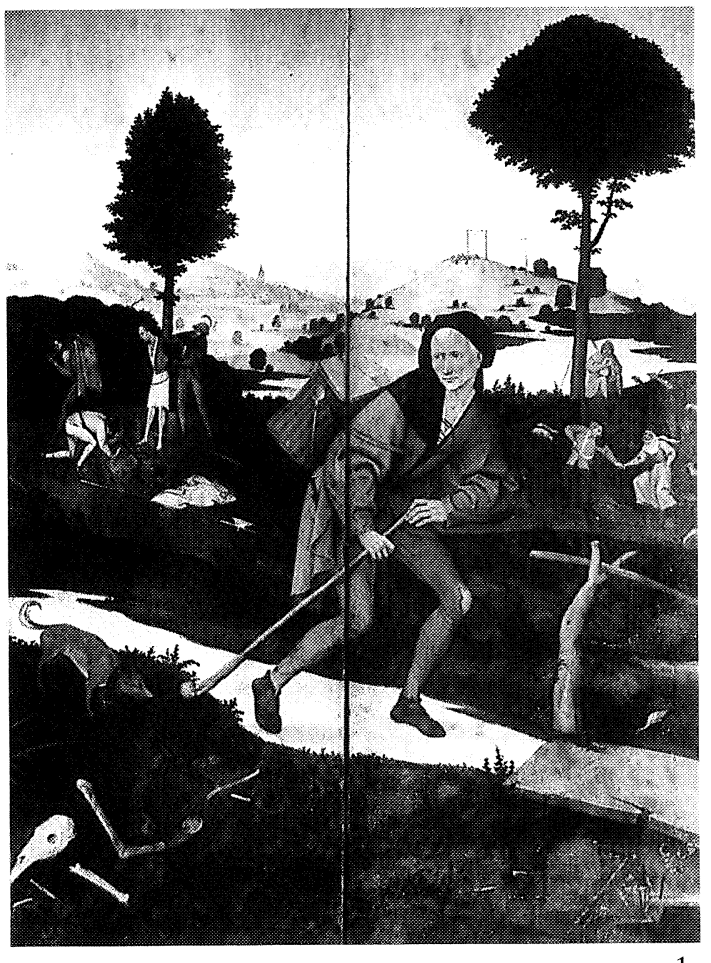

Elpelegrinó oela vida bumana.

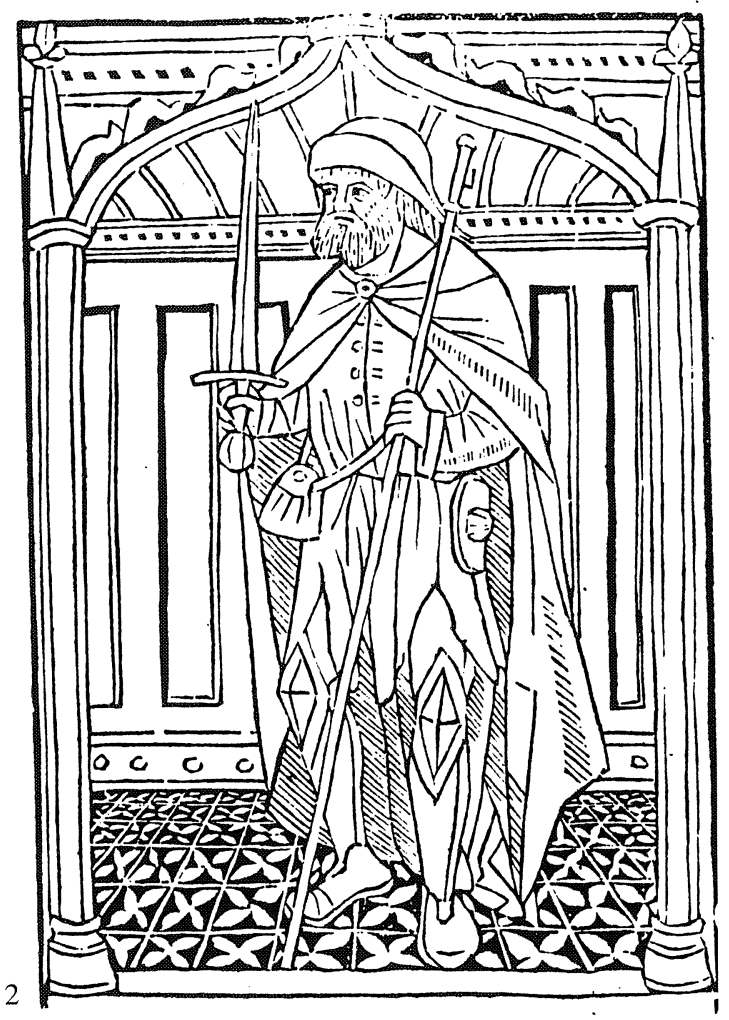

3
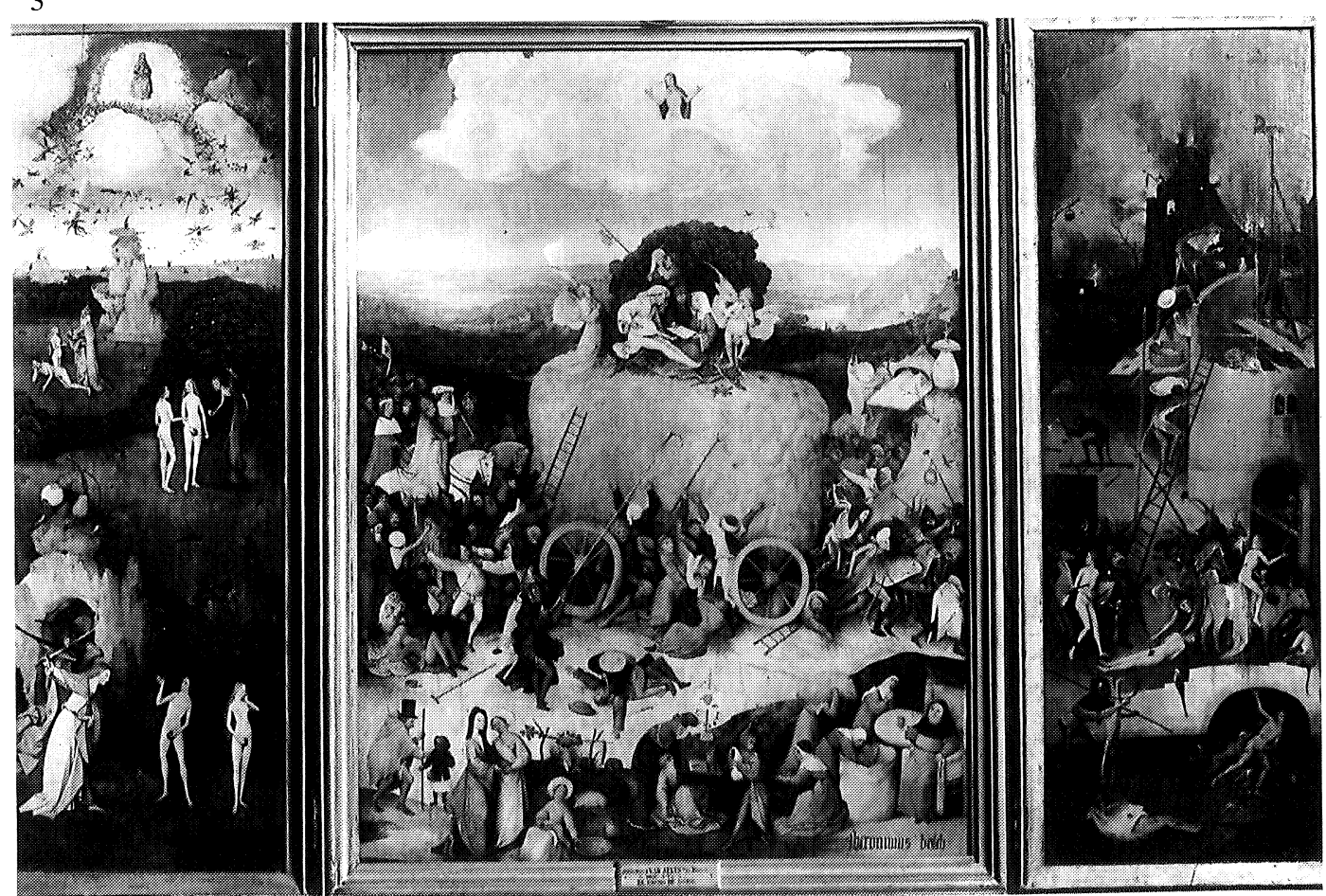

Figs. 1 y 3. El Bosco, El Carro del Heno. Puertas con el «caminante», y triptico abierto. Fig. 2. El Peregrino de la Vida Humana, grabado. El Escorial. Biblioteca 
mente, no hay quien haga el bien. Mira Javé desde lo alto, de los cielos a los hijos de los hombres para ver si hay entre ellos algún cuerdo que busque a Dios. Todos van descarriados, todos a una se han corrompido, no hay quien haga el bien, no hay uno solo ¿Se han vuelto del todo locos los obradores de la iniquidad, que devoran a mi pueblo como se com el pan, sin acordarse de Dios para nada? Ya temblarán con terror a su tiempo, porque está Dios con la generación de los justos" ${ }^{3}$. No cabe duda de que este Salmo se ajusta no sólo al tema de las puertas del Carro de Heno sino también a lo representado en su interior.

También se han preocupado los diferentes autores por el precedente iconográfico del «caminante» con su mochila, bastón y atacado por el perro. Para algunos está en la carta del "Mat» del Tarot, para otros en uno de los personajes del «Jardín del Amor» del Maestro E. S.; también en otro personaje de un grabado florentino de hacia 1460 representando a los "Hijos de Saturno»: en un emblema de Alciato representando «los buenos auspicios», o en otro de un margen minado del siglo XIV ${ }^{4}$.

Se ha comparado también literariamente con el caminante extraviado del Canto primero de la Divina Comedia: "a la mitad del camino de nuestra vida, perdido el recto sendero, me encontré en una oscura selva, duro y difícil sería contar cómo aquel paraje inhóspito, intrincado y áspero, así mi ánima, aun fugitiva, volvióse a mirar aquellos parajes» 5 .

No cabe duda que durante los períodos críticos de la humanidad, la literatura aporta temas semejantes. Modernamente podríamos pensar en el protagonista del Lobo estepario de Herman Hesse, acosado también por las acechanzas del mundo en que le tocó vivir.

Si la mayoría de los autores coinciden en el sentido fundamental de la escena -distanciándose solamente en pequeños matices fundamentados en el análisis de los diversos objetos que enriquecen la composición- así también están de acuerdo en que el Bosco debió basarse o inspirarse en alguna fuente literaria contemporánea, solo nos resta buscar aquella en que se aune el texto con la iconografía. Creemos haberla hallado en El Pelegrino de la Vida humana, de fray Vicente Mazuelo, publicado en Tolosa en 1490, cuya primera versión fue el Pélerinage de la Vie humaine de Guillaume de Deguilleville, siglo xIv. Se trata de un texto ilustrado con grabados que responde al mensaje del cuadro del Bosco ${ }^{6}$.

En efecto, en el tríptico del Bosco, el Caminante se ve acosado por la avaricia, la lujuria y la envidia: luego, en el interior, la humanidad desentendida del consejo Divino camina por la vida cayendo en los pecados capitales que, finalmente, serán juzgados.

El grabado de la portada del Peregrino presenta a éste con el bastón que según el texto, sirve para defenderse de los peligros (Fig. 2). El autor Fray Vicente Mazuelo al comienzo del libro nos dice que el original fue escrito por el «religioso y letrado muy profundo llamado fray Guillelmo de Guillevila de la abadía de Chalis cerca de la ciudad de Sant lis», por encargo de la princesa Juana Labal reina de Ihl'm y de Sicilia, duquesa de Avion y Obar, condesa de Provenza. Al final del libro declara que él ha seguido y traducido este texto del francés por encargo del «honorable Señor Maestre Enrrico Alemán». Este Maestre Enrique puede ser el platero, padre de Juan de Arfe, o el vidriero de las catedrales de Sevilla y Toledo, al que a partir de 1493 se le llama «Maestre Enrique». Ambos coinciden en fechas y nombre.

En los primeros capítulos el peregrino se encuentra con la Gracia de Dios, con la Razón ${ }^{7}$, con la Natura, con la Penitencia, con la Vanidad, con la Sabiduría culta y popular (Proverbio), y

\footnotetext{
3 I. Bango y F. Marías, Bosch. Realidad, símobolo y fantasía, Vitoria, 1982.

4 Loc. cit., nota 1.

5 Bango y Marías, loc. cit., nota 3.

6 Biblioteca de El Escorial. Incunable 29-V-6.

7 En estos momentos preparamos un trabajo sobre el texto y grabados del Peregrino en relación con otros textos similares de la época.
} 

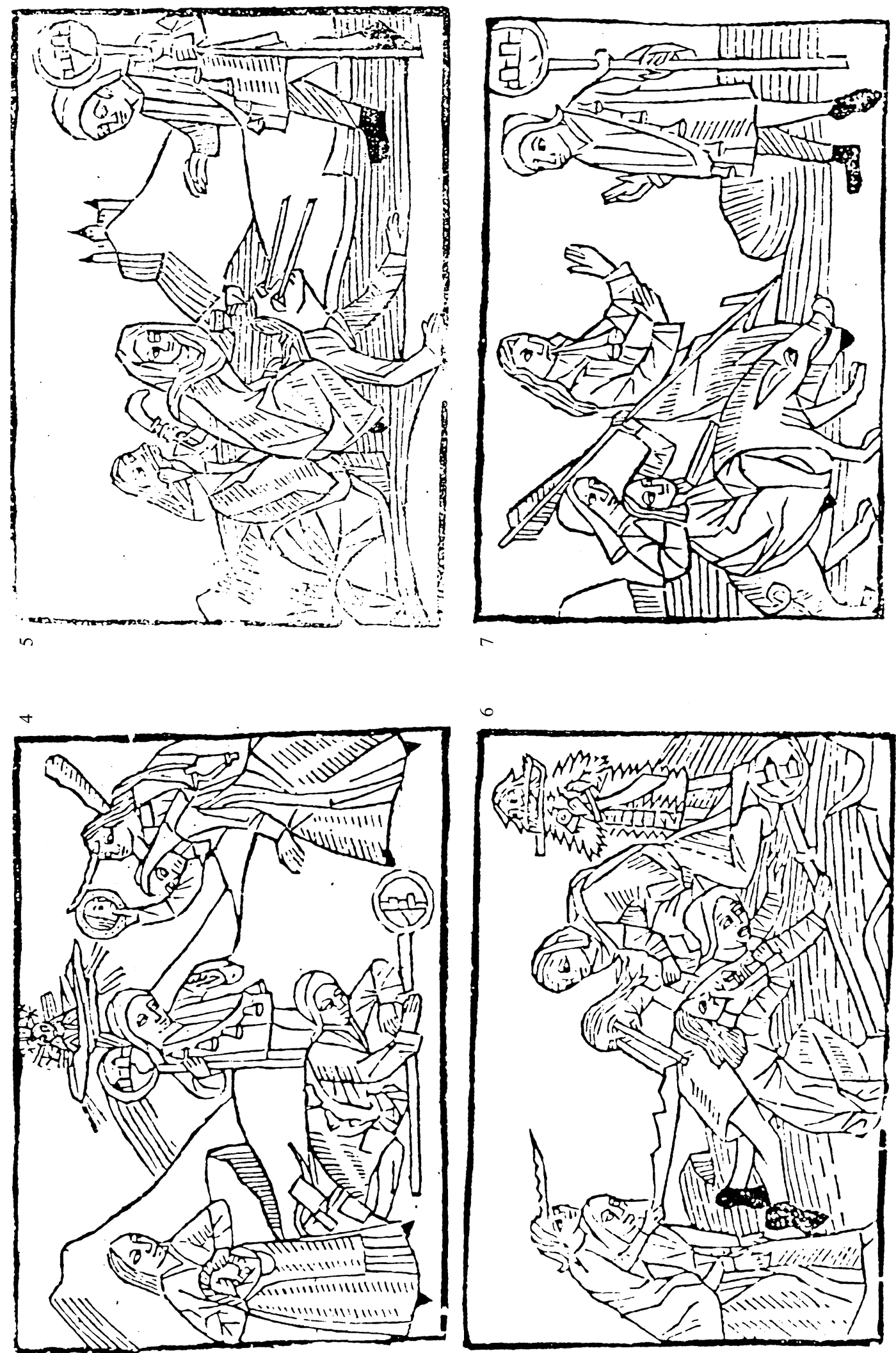

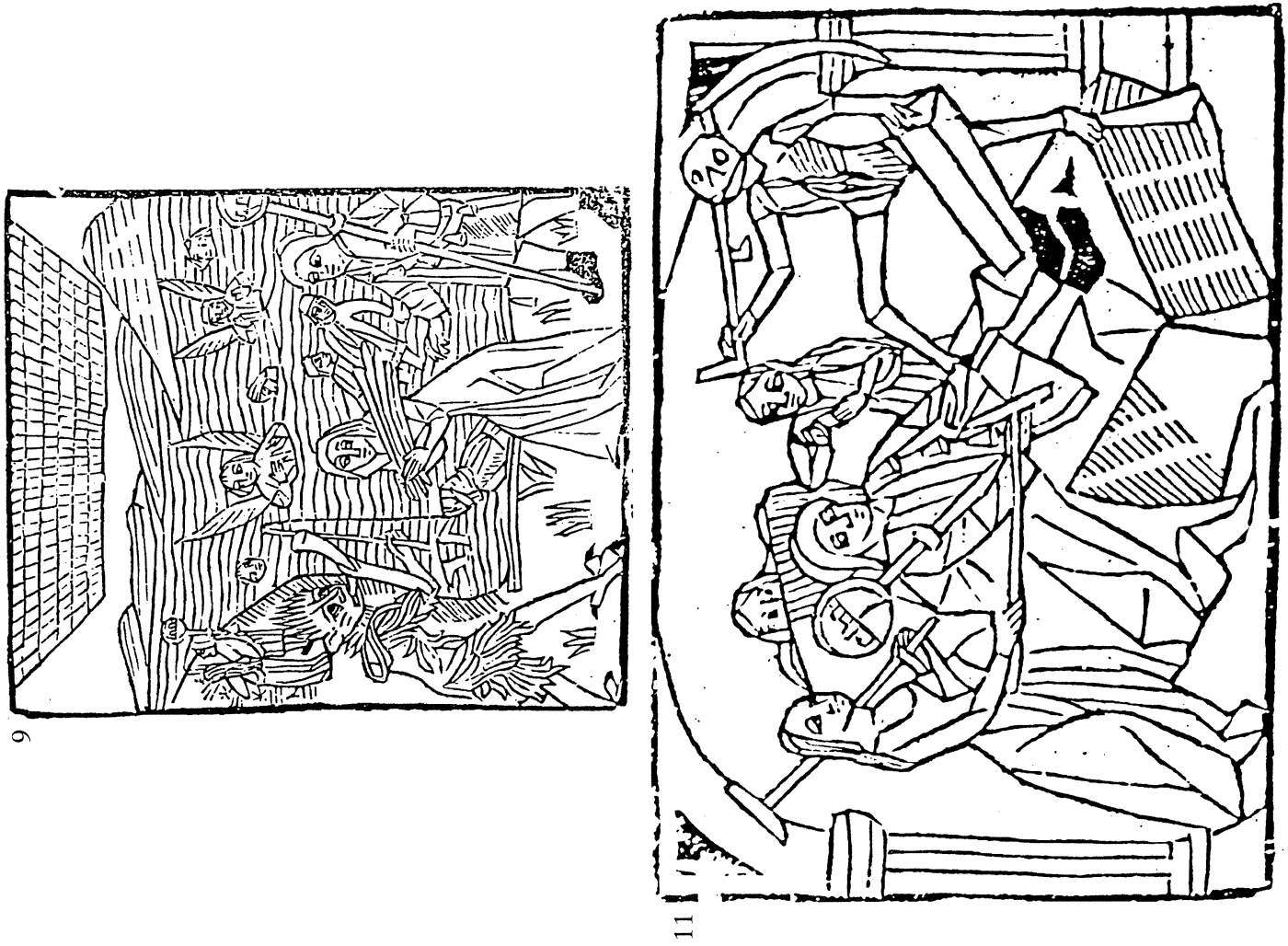

$\infty$

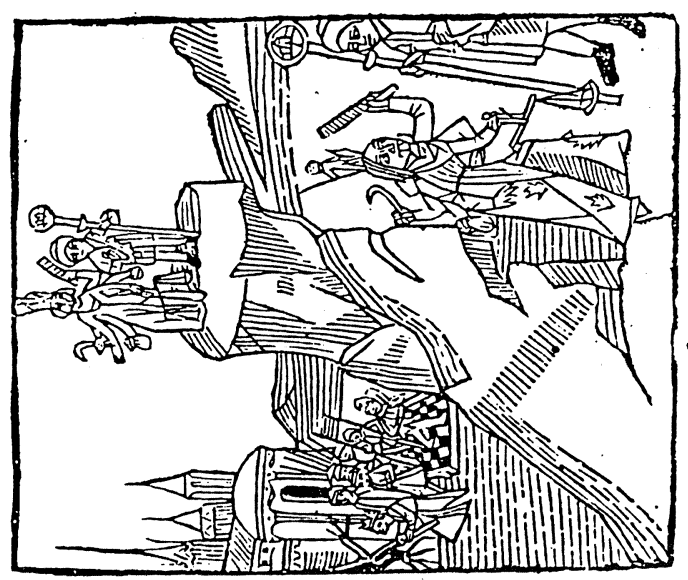

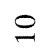

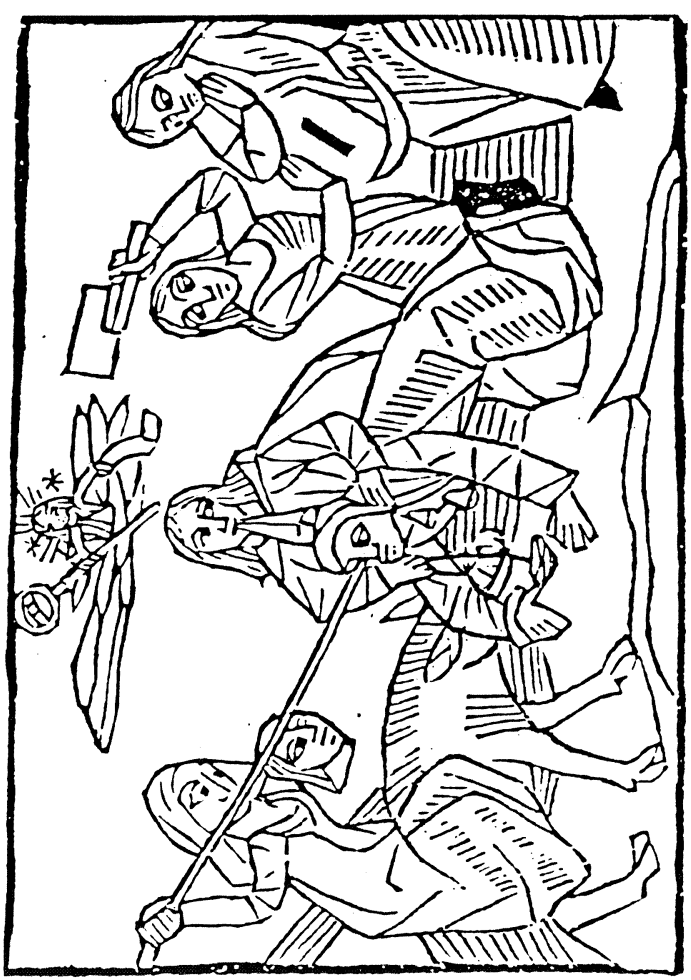


con el propio Aristóteles ${ }^{8}$, quienes le advierten y aconsejan antes de emprender su camino, del mismo modo que Dios advierte a Adán en el Paraíso del tríptico bosquiano, antes de que desarrolle su caminar.

En la segunda parte del texto la Razón empieza a enfrentarse con el Rudo Entendimiento, que parece encontrar paralelo con la incomprensión de Adán y su desobediencia en el Paraíso. Por fin, a raíz de esto, el peregrino es acosado por la Pereza, la Soberbia, la Lisonja, la Envidia, la Traición, la Murmuración, la Ira, la Avaricia, la Gula, la Lujuria y la Herejía, siendo estas tres últimas las que presentan grabados más significativos. Además de la representación de cada una de las escenas grabadas es muy ilustrativo el texto, donde cada una de ellas habla de sus quehaceres y conexiones quedando en evidencia que responden al contexto iconográfico tradicional de cada una de ellas (Figs. 4-10).

Todo ello conduce al peregrino a la enfermedad y muerte pero, por su arrepentimiento, y temor de Dios, «la Gracia Divina» le asiste, terminando el autor con la consideración didácticomoralizadora, de que todas las tribulaciones del peregrino en su caminar, sirvan de prevención a los que comiencen este peregrinar (Fig. 11).

No cabe duda de que es el mismo mensaje del Bosco, aunque en el cuadro no se haya podido dar paso al lenguaje culto que aparece en el texto con la presencia de la Razón, etc. En el Bosco el final es menos esperanzador que en el libro, pero ambos finales se deben, sin duda, al comitente al que estuvieron destinados las dos ediciones del Peregrino de la Vida Humana y, al del Bosco que hasta ahora desconocemos ${ }^{9}$.

Isabel Mateo Gómez Dpto. H. ${ }^{a}$ del Arte del C.S.I.C.

y Julián Mateo Viñes

\section{UN OBISPO DE LUGO EN SANTA CLARA DE TOLEDO: EL SEPULCRO DE FRAY JUAN ENRÍQUEZ}

La controvertida atribución del sepulcro episcopal conservado en el convento de Santa Clara la Real de Toledo, provocó el olvido de un personaje, Juan Enríquez, obispo de Lugo, que se halla fuertemente vinculado a dicha comunidad, a pesar de haber ejercido su actividad como prelado en una sede lejana a ese centro. No resulta extraño el que un obispo franciscano se inhume en un convento de clarisas, dada la común pertenencia a una orden mendicante, pero además, en el caso del obispo Juan Enríquez, existen motivos que justificarían la elección de un espacio en el mismo, y además en un emplazamiento preferente como es el coro. Entre éstos, cabría conceder prioridad, como se verá, a la autoridad moral de este obispo de origen franciscano dentro de la Orden. Sus vínculos con las clarisas toledanas, han de ser complementados con los datos que la propia genealogía del prelado aporta, ya que, varios descendientes de un tronco común que parte de Alfonso XI, se inhuman en ese convento, al que no por azar se adjudica el calificativo de real, pues dos de las hijas bastardas de Enrique II alcanzaron en él la condición de abadesas (cuadro 1).

8 La presencia de Aristóteles y la Razón tan en conexión con la Summa hace pensar que los dos autores o por lo menos el francés pueda ser de la Orden de Predicadores.

9 Buzzati, loc. cit., nota 1, de la noticia de que se ha relacionado con Cebete, un filósofo místico cuatrocentista. 